\title{
Relationship between the circulating levels of adenohypophyseal hormones in blood and in cerebrospinal fluid
}

\author{
ANDREA NICOLINI, ROBERTO BUONAGUIDI, MARCO FERDEGHINI, \\ ANGELO CARPI
}

From the Center of Nuclear Medicine and Institute of Neurosurgery, University of Pisa, Pisa, Italy

SUMMARY Concentrations of prolactin, follicle stimulating hormone, luteinising hormone and growth hormone were measured simultaneously in the serum and cerebrospinal fluid of 57 patients affected by neurologic disease without any pituitary or diencephalic involvement. Prolactin secretion was stimulated in another group of 12 patients using sulpiride or metoclopramide, and the hormone concentration was measured simultaneously in serum and in CSF during the test. Basal studies showed that the concentrations of prolactin, FSH, LH and GH in serum and in CSF were directly correlated ( $p$ varying from less than 0.001 to less than 0.05 ). A negative correlation was found between the molecular weight of hormones reported in this and in other studies and the natural logarithm of the CSF/serum hormone concentration ratios. During prolactin stimulation the correlation between serum and CSF concentration was maintained, nevertheless a higher increase of prolactin in blood than in CSF was observed. This last finding suggests that other mechanisms in addition to filtration from blood into CSF can be responsible for the presence of adenohypophyseal hormones in CSF.

Many reports show that pituitary and extrapituitary hormones circulate in cerebrospinal fluid. ${ }^{13}$ Nevertheless, the mechanisms by which these hormones enter the CSF circulation do not seem to be thoroughly investigated. Some possible mechanisms determining the presence of pituitary hormones in CSF are blood filtration at the choroid plexuses and retrograde transport from the pituitary to the CSF. ${ }^{414}$ is The latter mechanism is supported by the recent finding of direct anatomical ways connecting the pituitary and the CSF. ${ }^{16}{ }^{17}$ To contribute to the clarification of this question we studied the relationship between the circulating levels of some adenohypophyseal hormones in blood and in CSF, in basal conditions. This relationship was also studied during pituitary stimulation.

Address for reprint requests: Dr Roberto Buonaguidi, Institute of Neurosurgery, University of Pisa, Spedali S. Chiara, Via Roma n.57,56100 Pisa, Italy.

Received 7 July 1983 and in revised form 12 November 1983. Accepted 10 January 1984

\section{Materials and methods}

\section{Basal studies}

Concentration of prolactin (PRL), follicle stimulating hormone (FSH), luteinising hormone (LH) and growth hormone (GH) have been measured simultaneously in serum and in CSF in 57 patients with different neurologic diseases without any pituitary or diencephalic involvement. In some CSF samples it was not possible to measure all the hormones; the relative number of samples assayed for each hormone was 43, 28, 28, 21 for PRL, FSH, LH and GH respectively. CSF was taken during diagnostic lumbar puncture (40 patients) and during iodoventriculography or insertion of ventricle-atrial shunts from the lateral ventricle (17 patients). The patients studied were affected by intervertebral disks herniation (15), cerebrovascular diseases (6), cerebral neoplasms (19) and miscellaneous neurologic diseases (17).

Studies during prolactin pituitary stimulation

These studies were performed in 12 patients who received sulpiride or metoclopramide prior to lumbar puncture. Sulpiride was administered to seven patients, in daily doses varying from 150 to $300 \mathrm{mg}$, from one to three days; metoclopramide was given to five patients, in daily doses of $30 \mathrm{mg}$ for one to two days. PRL concentrations in serum 
Table 1 CSF hormonal values $(\mathrm{ng} / \mathrm{ml})$ above the limits of detectability, the corresponding serum levels $(\mathrm{ng} / \mathrm{ml})$ and their ratios.

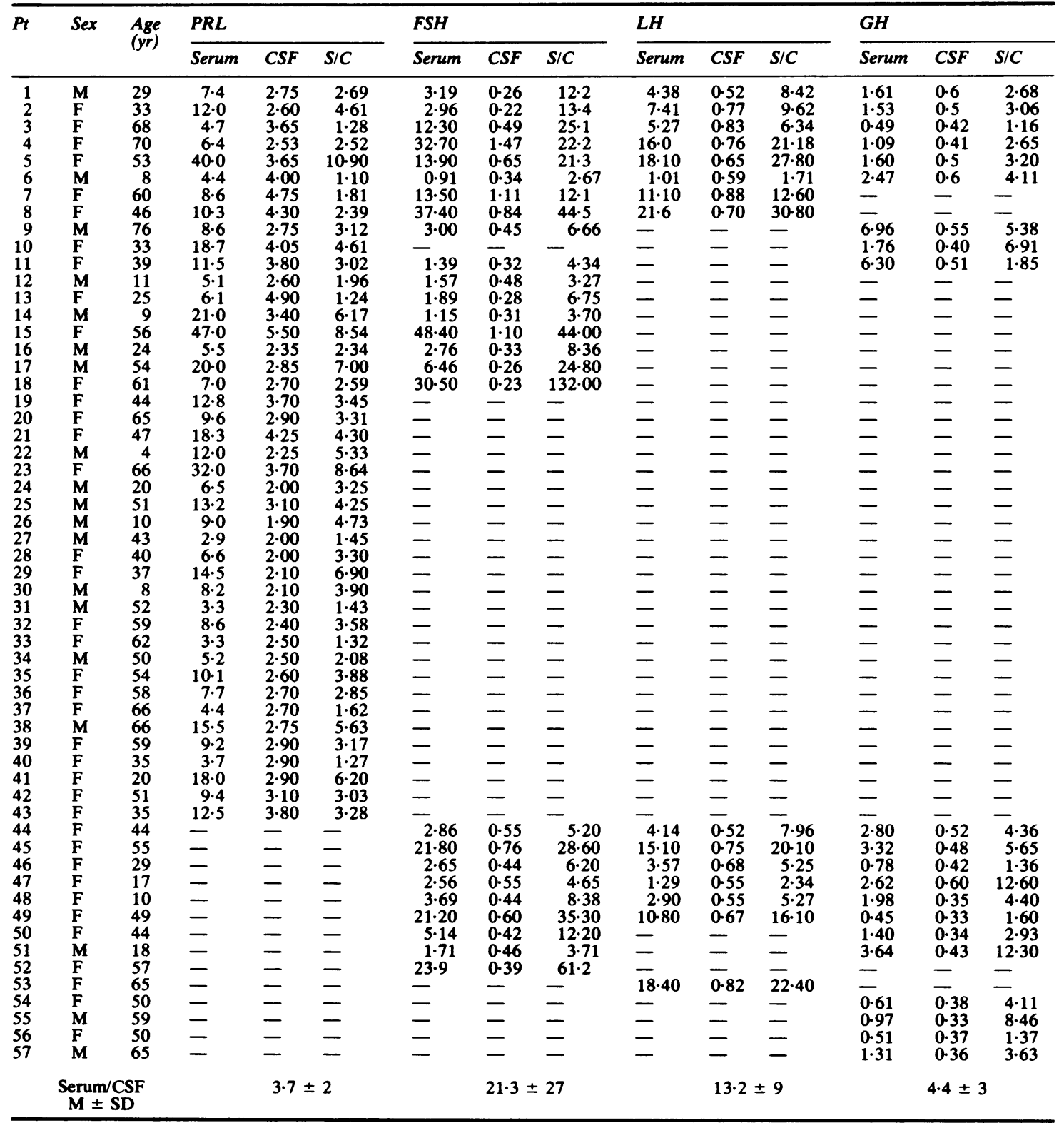

and in CSF were simultaneously measured in these patients at the end of the stimulation period, when monitoring of serum PRL levels showed that steady serum PRL levels were reached. None of the patients studied had received medication or anaesthesia except a very young patient in the basal study group (pt. 22, table 1) who had received medication (promethazine hydrochloride $25 \mathrm{mg}$ plus atropine sulphate $0.5 \mathrm{mg}$ iv) and anaesthesia (thiopental sodium $100 \mathrm{mg}$ plus succinylcholine $25 \mathrm{mg}$ iv and fluothane) before iodoventriculography.

Radioimmunoassay of adenohypophyseal hormones was performed using RIA kits supplied by Sorin Biomedica, Italy (for LH, FSH, GH) and by Biodata, Italy (for PRL). In our laboratory, before the menopause, the upper normal limits for FSH, LH and PRL serum concentrations are $9.5,23$ and $25 \mathrm{ng} / \mathrm{ml}$ respectively; after the menopause 
Table 2 Classification of the patients according to pathological lesions

\begin{tabular}{|c|c|c|}
\hline Pathological lesions & $N$ & Patients \\
\hline $\begin{array}{l}\text { Intervertebral disks } \\
\text { herniation } \\
\text { Cerebrovascular }\end{array}$ & 15 & $\begin{array}{l}7,9,10,19,20,31,33,34,36 \\
37,39,40,42,44,54\end{array}$ \\
\hline $\begin{array}{l}\text { disease } \\
\text { Tumours of CNS }\end{array}$ & $\begin{array}{r}6 \\
10\end{array}$ & \multirow{2}{*}{$\begin{array}{l}\text { 1, 12, 32, 38, 45, 55 } \\
6,14,15,16,17,18,24,25,26,28 \\
29,30,35,43,49,51,53,56,57 \\
46,50 \text { (multiple sclerosis); 21, 52 } \\
\text { (amyotrophic lateral sclerosis); } \\
5,23 \text { (dorsal epidural } \\
\text { meningiomas); } 2,27 \text { (pseudo- } \\
\text { tumour cerebri); 11, 41 } \\
\text { (vestibular symptoms); } 8 \\
\text { (porencephaly); } 3 \text { (peripheral } \\
\text { nerve paralysis); } 4 \text { (cervical } \\
\text { myelopathy); 47, 48 (epilepsy); } \\
13 \text { (pharmacological coma); 22 } \\
\text { (posterior fossa cyst) }\end{array}$} \\
\hline Miscellaneous diseases & 17 & \\
\hline
\end{tabular}

these values are 53,21 and $15 \mathrm{ng} / \mathrm{ml}$ respectively. In men the upper normal limits for these hormones are 2.8, 2.9 and $15 \mathrm{ng} / \mathrm{ml}$. The upper limit of the normal range is 6 $\mathrm{ng} / \mathrm{ml}$ for $\mathrm{GH}$. The intraassay and interassay coefficients of variation are $4.5 \%$ and $9 \%, 6 \%$ and $11 \%, 5 \%$ and $13 \%$, $5 \%$ and $10 \%$ for PRL, FSH, LH and GH respectively. The limits of detectability of the hormone concentrations were $0.5,0.21,0.2$ and $1 \mathrm{ng} / \mathrm{ml}$ for LH, FSH, GH and PRL respectively.

\section{Results}

Table 1 shows the hormonal serum and CSF values of the studies performed in basal conditions. Table 2 groups the patients according to their pathology. Fifteen of the 120 hormonal determinations in the CSF were below the limit of detectability of the RIA kits used. The undetectable values were observed in the LH and FSH determinations (13 and 2 values respectively). All the CSF concentration values of GH and PRL were within the limits of detectability of the kits used. The CSF concentration values of all the hormones studied showed no difference either as regards the various pathological conditions examined or as to the sites from which the samples were withdrawn. Table 1 shows that hormone concentrations in CSF tend to be low or high according to the corresponding values in serum. Accordingly serum $\mathrm{LH}$ mean concentrations $(9.4 \pm 6.9 \mathrm{SD})$ of the patients with measurable CSF concentrations

Table 3 Coefficients and statistical significance of the correlations between serum and measurable CSF concentrations of adenohypophyseal hormones

\begin{tabular}{llll}
\hline Hormone & $n$ & $r$ & $p$ \\
\hline PRL (ng/ml) & 43 & 0.49 & $<0.001$ \\
FSH $(\mathbf{n g} / \mathrm{ml})$ & 26 & 0.65 & $<0.001$ \\
LH (ng/ml) & 15 & 0.52 & $<0.05$ \\
GH (ng/ml) & 21 & 0.52 & $<0.05$ \\
\hline
\end{tabular}

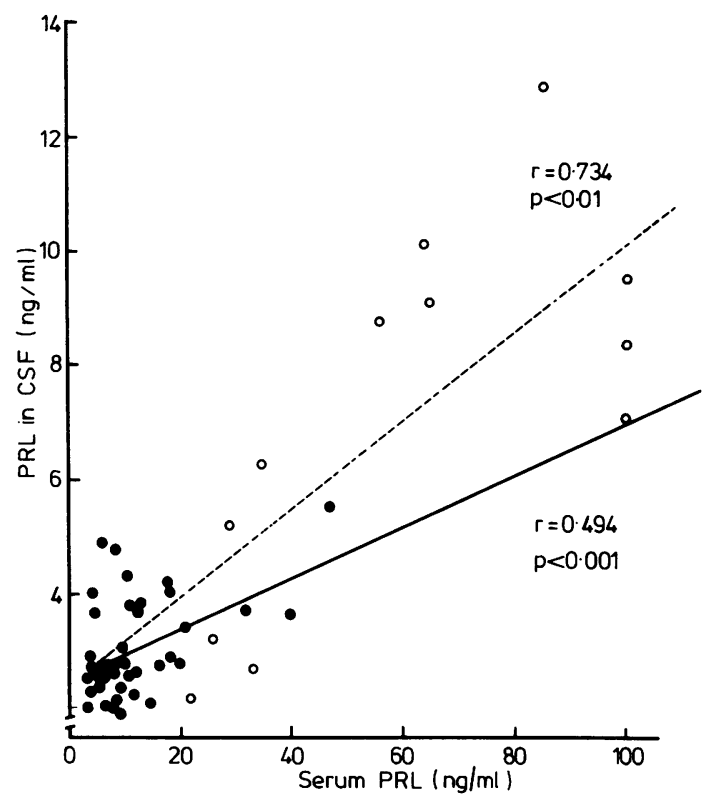

Fig. 1 Correlation between serum and CSF PRL concentrations. $\bullet-=$ basal $P R L$ secretion. $\circ--—=$ serum $P R L$ secretion during pharmacological stimulation.

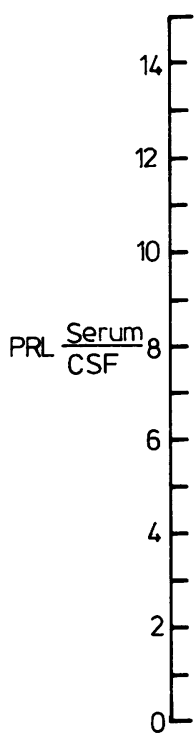

8
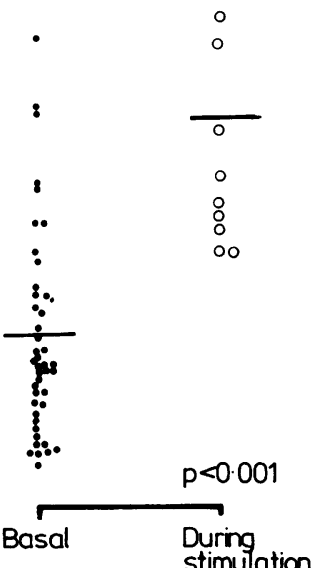

Fig 2 Ratio between serum and CSF PRL concentrations. - = basal serum PRL secretion o serum PRL secretion during pharmacological stimulation. Horizontal bars indicate the mean values. 
are significantly higher than those in the patients with undetectable CSF values $(4 \cdot 6 \pm 5$ SD) $(p<$ 0.05 unpaired $t$ test). A significant positive correlation was found between serum and measurable CSF concentrations values of all the hormones (Table 3). The measurable FSH and LH CSF concentrations were significantly correlated with the age of the patients ( $p<0.01$ and $p<0.05$ respectively). During pharmacological stimulation of PRL secretion, a positive correlation was found between the hormone concentration in serum and in CSF $(r=0.734 p<$ $0 \cdot 01)$. When all the studies were taken into account (during basal and stimulated PRL secretion), a direct correlation was also found between PRL concentration in serum and in CSF (fig 1). The ratio serum/CSF PRL concentration was higher during stimulated PRL secretion than during basal PRL secretion (fig 2). No correlation was found between the duration of pharmacological PRL stimulation and the ratio serum/CSF PRL concentrations.

\section{Discussion}

In this study correlations have been found between serum and CSF concentrations of PRL, FSH, LH and $\mathrm{GH}$ in basal conditions although some CSF determinations were close to the detection limit of the assay used. A correlation between PRL, GH and TSH concentrations in serum and in CSF in basal studies have been reported by other authors. ${ }^{341418-20}$ Correlations between serum and CSF concentrations of FSH, LH and ACTH have not been found in most of the studies. ${ }^{1521}$ In our study it is likely that elderly menopausal patients with relatively high serum levels of FSH and $\mathrm{LH}$ have increased the range of concentrations explored, helping to detect the correlation between serum and CSF values. The correlation between serum and CSF PRL concentrations in patients with basal PRL secretion is significant because of the three patients with slight elevation of PRL serum levels (Pt. 5, 15, 23 table 1). Therefore we cannot affirm that this correlation is maintained when serum PRL levels are in normal range. However, the finding that most of the adenohypophyseal hormones studied show CSF concentrations related to those of serum seems to favour the hypothesis of the hormonal filtration at the choroid plexuses from blood into CSF. The hypothesis of hormonal filtration from blood into CSF is also suggested by fig 3 which shows the correlation between the CSF/serum ratio and the molecular weight of the hormones studied together with other pituitary and extrapituitary hormones. The CSF/serum ratios for ACTH, insulin, calcitonin, HCG and HCS are those reported in different studies carried out in basal

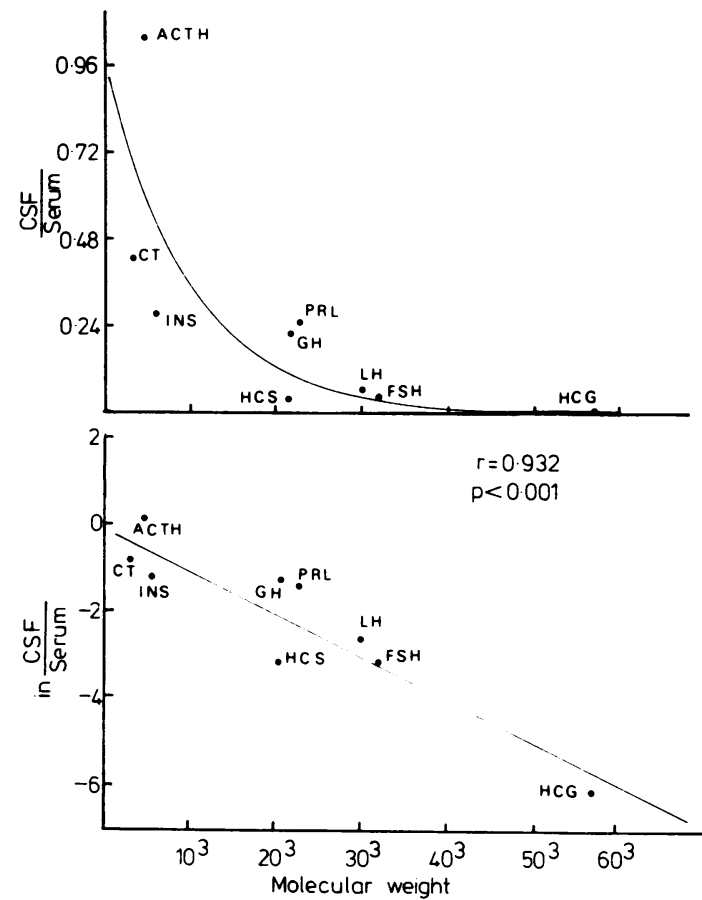

Fig 3 Upper panel: correlation between the molecular weight of pituitary and extrapituitary hormones and their $C S F /$ serum concentration ratios. The regression line is derived from the equation: $\mathrm{Ln} C S F /$ serum $=0.56-$ $0.00001 \times$ molecular weight.

Lower panel: correlations between the molecular weight and the natural logarithm of the CSF/serum concentration ratios for pituitary and extrapituitary hormones.

In both the panels the CSF/serum concentration ratios of $P R L, F S H, L H$ and $G H$, are those reported in this study; the CSF/serum ratios of ACTH,CT, INS, HCS and HCG are derived from literature.

Abbreviations (extrapituitary hormones): $C T=$ calcitonin; INS = insulin; HCS = human chorionic

somatomammotropin; HCG = human chorionic gonadotropin.

conditions. ${ }^{18914}$ It can be seen that an inverse correlation is found between the two parameters (CSF/ serum ratio and molecular weight) when all the hormones are taken into account. This finding suggests that the hormonal molecular weight affects the $\mathrm{CSF} /$ serum ratio. As the same correlation has been reported $^{22}$ between the plasma/CSF concentration ratio and the molecular weight of blood proteins it could be inferred that the adenohypophyseal hormones, which have a molecular weight less than that of albumin, enter the CSF by the same route as the various blood proteins. Nevertheless a PRL increase higher in blood than in CSF and quite different PRL serum/CSF ratios (ranging from 5.5 to 14.2) are 
found for increased serum concentrations (fig 2). These findings cannot be explained by a slowly increasing PRL passage into CSF as no correlation in our study has been observed between the duration of PRL stimulation and the serum/CSF ratio and it has been reported in animals that peak plasma PRL values occur 30 min after pituitary stimulation followed by the peak CSF PRL levels with a delay of 60 min. ${ }^{23}$ The same finding also has been reported for insulin in basal patients. ${ }^{8} \mathrm{~A}$ lower CSF/serum PRL ratio in basal studies could hypothetically be due to an essay error for lower PRL levels; but if this methodological limit did not occur these last observations disagree with the hypothesis of only passive diffusion and seem to suggest that also other mechanisms (that is, saturable or retrograde transport, extra-pituitary cerebral production) can be responsible for the presence of the hormone in CSF. A similar suggestion derives from the PRL and GH mean serum/CSF ratios which, in our study (table 1), and also in others, ${ }^{34718}$ are lower than that of HCS reported in the literature ${ }^{14}$ in spite of the same molecular weight. Also, since most peptide hormones secreted from the brain, like HCS, do not show any correlation between their serum and CSF values $^{9-112425}$ it could be that the blood-CSF barrier differs depending on the hormone involved and on its cerebral or extra-cerebral origin.

In conclusion our study shows that serum FSH, LH, GH and PRL hormone concentrations seem to influence the levels in the CSF and supports the hypothesis that a different mechanism affects the presence of PRL in CSF. It is, however, evident that further studies are necessary to define better the actual contribution of filtration and of the other hypothesised mechanisms of the entry of the adenohypophyseal hormones into the CSF.

\section{References}

' Kleerekoper M, Donald RA, Posen S. Corticotrophin in cerebrospinal fluid of patients with Nelson's syndrome. Lancet 1972;1:74-6

${ }^{2}$ Smith AG, Shunster S. Immunoreactive betamelanocyte-stimulating hormone in cerebrospinal fluid. Lancet 1976;1:1321-2.

${ }^{3}$ Schaub C, Bluet-Pajot MT, Szikla G, Lornet C, Talairach J. Distribution of growth hormone and thyroid-stimulating hormone in cerebrospinal fluid and pathological compartments of the central nervous system. J Neurol Sci 1977;31:123-31.

4 Assies J, Schellekens APM, Touber JL. Prolactin in human cerebrospinal fluid. J Clin Endocrinol Metab 1978;46:576-86.

5 Liira J, Leppaluoto J, Hyppa MT. Hypothalamic and pituitary hormones in human CSF. Acta Neurol Scand. 1978;(suppl)67, 57:120-1.

- Luboshitzky R, Barzilai D. Suprasellar extension of tumor associated with increased cerebrospinal fluid activity of LH and FSH. Acta Endocrinol
1978;87:673-81.

${ }^{7}$ Linfoot JA, Garcia JF, Wei W, et al. Human growth hormone levels in cerebrospinal fluid. J Clin Endocrinol Metab 1970;31:230-2.

${ }^{8}$ Greco AV, Ghirlanda G, Fedeli G, et al. Insulin in the cerebrospinal fluid of man. Eur Neurol 1979;3:303-7.

9 Paulinac DM, Lenhard LW, Parthemore JG, Deftos LJ. Immunoreactive calcitonin in human cerebrospinal fluid. J Clin Endocrinol Metab 1980;38:717-20.

${ }^{10}$ Shigheto M, Junko N, Akira M, et al. Calcitonin in plasma and cerebrospinal fluid from normal subjects and patients with medullary thyroid carcinoma: possible restriction of calcitonin by the blood-brain barrier. J Clin Endocrinol Metab 1982;55:594-6.

" Kruse-Larsen C, Rehfeld JF. Gastrin in human cerebrospinal fluid: lack of correlation with serum concentrations. Brain Res 1979;176:189-91.

12 Bagshawe KD, Harland S. Immunodiagnosis and monitoring of gonadotrophin-producing metastases in the central nervous system. Cancer 1976;38:112-8.

${ }^{13}$ Berkowitz RS, Osathanondh R, Goldstein DP, et al. Cerebrospinal fluid human chorionic gonadotropin levels in normal pregnancy and choriocarcinoma. Surg Gynecol Obstet 1981;153:687-9.

14 Assies J, Schellekens APM, Touber JL. Protein hormones in cerebrospinal fluid: evidence for retrograde transport of prolactin from the pituitary to the brain in man. Clin Endocrinol 1978;8:487-91.

15 Allen JP, Kendall JW, McGilvra R, et al. Immunoreactive ACTH in cerebrospinal fiuid. J Clin Endocrinol Metab 1974;38:586-93.

${ }^{16}$ Bergland RM, Davis SL, Page RB. Pituitary secretes to brain. Lancet 1977;1I:276-8.

${ }^{17}$ Bergland RM, Page RB. Can the pituitary secrete directly to the brain? (affirmative anatomical evidence). Endocrinology 1978;102:1325-38.

18 Schroeder LL, Johnson JC, Malarkey WB. Cerebrospinal fluid prolactin: a reflection of abnormal prolactin secretion in patients with pituitary tumors. $J$ Clin Endocrinol Metab 1976;43:1255-60.

19 Jordan RM, McDonald SD, Stevens EA, Kendall JW. Cerebrospinal fluid prolactin: a reevaluation. Arch Intern Med 1979;139:208-11.

${ }^{20}$ Login IS, MacLeod RM. Prolactin in human and in rat serum and cerebrospinal fluid. Brain Res 1977;132:477-83.

21 Jordan RM, Kendall JW, Seaich JL, et al. Cerebrospinal fluid hormone concentration in the evaluation of pituitary tumors. Ann Intern Med 1976;85:49-55.

22 Felgenhauer K. Protein size and cerbrospinal fluid composition. Klin Wochenschr 1974;52:1158-64.

${ }^{23}$ Kalin NH, Burns RS, Risch SC, Cosgrove SA, Warden $D$, Murphy DL. The relationship between blood and cerebrospinal fluid prolactin in non human primates. Life Sci 1982;31:159-63.

${ }^{24}$ Goodner CJ, Berrie MA. Failure of rat hypothalamic tissues to take up labeled insulin in vivo or to respond to insulin in vitro. Endocrinology 1977;101:605-12.

${ }^{25}$ Ziegler MG, Lake CR, Wood TH, Brook BR, Ebert MH. Relationship between norepinephrine in blood and cerebrospinal fluid for the presence of a bloodcerebrospinal barrier for norepinephrine. $J$ Neurochem 1977;28:677-9. 